\title{
El contrato de concesión de obras públicas y su financiación privada
}

\author{
Miguel Ángel Ruiz López \\ Administrador Civil del Estado
}

Sumario: I. INTRODUCCIÓN: LA LEY 13/2003, DE 23 DE MAYO, REGULADORA DEL CONTRATO DE CONCESIÓN DE OBRAS PÚBLICAS Y SU INCIDENCIA EN EL MARCO JURÍDICO DE LA CONTRATACIÓN ADMINISTRATIVA. 2. CARACTERÍSTICAS DE LA REGUALACIÓN DEL CONTRATO DE CONCESIÓN DE OBRAS PÚBLICAS. a) Existencia de una obra púbica. b) El riesgo concesional. c) El equilibrio económico concesional. d) Diversificación de las fuentes de financiación. 3. LOS NUEVOS MECANISMOS DE FINANCIACIÓN DE OBRAS PÚBLICAS: EL RÉGIMEN ECONÓMICO-FINANCIERO DEL CONTRATO Y LA FINANCIACIÓN PRIVADA. a) Emisión de obligaciones. b) Incorpoarción a títulos negociables de los derechos de crédito del concesionario. c) Hipoteca de la concesión. d) Los créditos participativos. 4. VALORACIÓN GENERAL DE LA LEY 13/2003 ANTE EL HORIZONTE DE UNA NUEVA LEY DE CONTRATOS DEL SECTOR PÚBLICO.

\section{INTRODUCCIÓN: LA LEY 13/2003, DE 23 DE MAYO, REGULADORA DEL CONTRATO DE CONCESIÓN DE OBRAS PÚBLICAS Y SU INCIDENCIA EN EL MARCO JURÍDICO DE LA CONTRATACIÓN ADMINISTRATIVA}

La contratación pública constituye uno de los ámbitos más importantes de la actuación administrativa en el momento presente. Su significado económico y social, la complejidad inmanente al carácter básico del régimen jurídico de los contratos administrativos al amparo del artículo 149.1.18 de la Constitución Española, así como la incidencia que sobre la financiación de obras públicas tienen las normas comunitarias relativas a la contención del déficit público, ponen de relieve que cualquier modificación normativa que afecte a este sector alcanza una transcendencia suficiente como para recabar el interés de los operadores jurídicos.

En este contexto se sitúa la Ley 13/2003, de 23 de mayo, reguladora del contrato de concesión de obras públicas (en adelante, Ley 13/2003), que no sólo comporta una modificación del régimen jurídico vigente en materia de contratación administrativa, sino que por vez primera en nuestro ordenamiento jurídico introduce diversas técnicas de financia- 
ción en la construcción y explotación privadas de infraestructuras públicas.

Como señala su Exposición de Motivos, la ley se justifica con las siguientes palabras:

«El desarrollo económico sostenido y la mejora de la calidad de vida no pueden desvincularse de la creación de infraestructuras y de la prestación a los ciudadanos de servicios considerados esenciales, funciones ambas que tienen en los poderes públicos los responsables más cualificados. El protagonismo de las distintas Administraciones Públicas no debe ni puede excluir, sin embargo, para asegurar una mejor respuesta a las demandas de la sociedad, el papel relevante que corresponde a la propia sociedad civil en general $y$, en el plano económico, al empresario privado, colaborador obligado y tradicional de la Administración a través de las distintas fórmulas recogidas en nuestra legislación».

En este sentido, la ley pretende dar respuesta al crecimiento constante de la demanda de transporte, tanto de personas como de mercancías, en un mercado cada vez más abierto a la competencia ${ }^{1}$; crecimiento que a su vez genera una demanda cada vez más importante de obras públicas viarias, ferroviarias, portuarias y aeroportuarias, así como un incremento proporcional en las necesidades financieras. No en vano, la aprobación por el Ministerio de Fomento del Plan Estratégico de Infraestructuras y Transporte 2005-2020 supondrá una inversión pública cercana a 248.892 millones de euros, de los que aproximadamente un $20 \%$ está previsto que sea costeado por el sector privado. Otro tanto ocurre con otros Planes aprobados en los últimos años, tales como el Plan Hidrológico Nacional o el Plan Nacional de Regadíos, que en su conjunto representan un volumen nada desdeñable de contratación pública.

No es nueva la apelación al sector privado en el repertorio de instrumentos que a lo largo de la historia han articulado una estrecha colaboración con los poderes públicos en la satisfacción del interés general. Así, la esencia de la concesión administrativa, utilizada ya en 1845 , y que fue objeto de desarrollo con carácter general en la Ley General de Obras

\footnotetext{
${ }^{1}$ Así, el Libro Blanco sobre la política europea de transportes coincide en que la nueva realidad económica demanda un protagonismo creciente de las Administraciones Públicas en la regulación de unos mercados abiertos a la competencia. Lo hace con las siguientes palabras:

«En los últimos veinte años, hemos pasado de una economía de almacenamiento a una economía de producción ajustada (flujos). Este fenómeno se ha ampliado con el movimiento de deslocalización de algunas industrias -especialmente para los bienes con fuerte intensidad de mano de obra- en busca de costes de producción más bajos...».

Añade que si la Unión Europea no adopta ninguna medida en esta materia para utilizar de forma racional las ventajas de cada medio de transporte, el aumento de tan sólo el tráfico de camiones alcanzará casi un $50 \%$ con respecto a su nivel de 1998 .
} 
Públicas de $1877^{2}$, ha sido dar entrada al sector privado en la financiación de las obras públicas, entregando «a los particulares una esfera funcional de competencia atribuida a la Administración pública o, dicho de otro modo, de investirles de una función pública, viniendo a ser de esta manera un término medio entre la gestión directa y la pura libertad privada»3.

Mediante el contrato de concesión la Administración confía al concesionario (o adjudicatario) la construcción y explotación de la obra reconociéndole el derecho a percibir unas tarifas de los usuarios, de tal manera que aquél financia en primera instancia las obras y recupera después su inversión, incrementada en un porcentaje determinado, a través del cobro a estos últimos de peajes o cánones.

Uno de los aspectos más novedosos de esta Ley 13/2003 es su carácter troncal u horizontal, ya que nace con la vocación de servir de marco normativo común a todas las obras públicas, sin perjuicio de las especialidades precisas en cada caso concreto. La norma, siendo además de aplicación a las concesiones que puedan licitar las Administraciones públicas territoriales y las Entidades de Derecho Público, en razón de su carácter básico, pretende constituir el marco unitario y estable para incentivar la participación del sector privado en todo tipo de obras públicas ${ }^{4}$, y por ello su objetivo declarado es extender a todas ellas el sistema concesional de financiación que en la actualidad se emplea para la construcción de autopistas.

En términos generales, la puesta al día de la institución concesional determina que la financiación y construcción de obras públicas se instrumente a través de alguna de las siguientes modalidades:

a) Construcción mediante contrato de obras y pago con cargo a fondos públicos del Estado, de las Comunidades Autónomas o de las Entidades Locales.

\footnotetext{
${ }^{2}$ Un estudio sobre la figura de la concesión de obra pública desde una perspectiva histórica puede verse en P. MENÉNDEZ. y P. FERNÁNDEZ ACEVEDO, «Análisis histórico-jurídico de la concesión de obra pública», en A. MENÉndez MenÉNDEZ, Comentarios a la nueva Ley 13/2003, de 23 de mayo, reguladora del contrato de concesión de obras públicas, Ed. Civitas, Madrid, 2003, pp. 29-80.

${ }^{3}$ A. MenÉNDEZ MENÉNDEZ, «La financiación privada en la construcción de obras públicas y la regulación del contrato en su contexto social y económico», en Ídem (director): Comentarios a la nueva Ley 13/2003, op. cit., 11.

${ }^{4}$ Vid., F. Alonso Colomer, «Una última reflexión sobre la vocación y la incidencia de la nueva ley», en A. MENÉndez MenÉNDEZ, (director): Comentarios a la nueva Ley 13/2003, op. cit., p. 432 y ss. Este autor resume el ámbito objetivo de la ley, esto es, las obras públicas susceptibles de construirse en régimen de concesión, distinguiendo entre las obras públicas de carácter lineal (infraestructuras viarias y de conducción de agua) y obras públicas concentradas que sirven de soporte para actividades o servicios diversificados (espacios portuarios y aeroportuarios).
} 
b) Construcción bajo el régimen especial de abono total del precio, en que el constructor obtiene su propia financiación y la Administración realiza un pago único para la adquisición de la obra terminada.

c) Sistemas de construcción y gestión con financiación privada y supervisión y control públicos, que se desarrollan en la Ley $13 / 2003$.

En tal motivación de la ley anidan los nuevos postulados de la doctrina del Derecho Administrativo Económico ${ }^{5}$ y el entendimiento que la misma realiza de los nuevos equilibrios entre lo público y lo privado en lo que afecta a la planificación, construcción y explotación de obras públicas por medio de la concesión, que es figura jurídica de primer orden en la defensa del interés público que sirven las Administraciones Públicas y al que contribuyen también las empresas concesionarias, amén de los intereses privados que les son propios.

Desde estas premisas se aborda el estudio de la Ley 13/2003 en la presente aproximación a su régimen jurídico y a los nuevos mecanismos de financiación privada en la construcción de obras públicas. Se parte para ello de la consideración de que la iniciativa privada no sólo se admite sino que se estimula abiertamente a la vista de los principios inspiradores de esta nueva regulación. Sirvan como muestra cuatro de los aspectos más significativos de la ley en los que rezuma la búsqueda de un equilibrio entre el interés público y el interés privado:

- El nuevo artículo 222, en relación con el 227 del Texto Refundido de la Ley de Contratos de las Administraciones Públicas, aprobado por el Real Decreto Legislativo 2/2000, de 16 de junio (en adelante, LCAP), admite la iniciativa privada en la construcción y explotación de una obra pública en régimen de concesión. Para ello se exige la aportación de un estudio de viabilidad, acreditativo de la seriedad y factibilidad de la propuesta. La Administración se reserva el control de esa factibilidad (artículo 227.5 LCAP) y viene obligada al resarcimiento de los gastos en que hubiera podido incurrir el autor del estudio, incrementados en un $10 \%$, en caso de que no resultara adjudicatario.

\footnotetext{
5 Vid., en Estudios de Derecho Público Económico. Libro Homenaje al Prof. Dr. D. Sebastián Martín-Retortillo, Editorial Civitas, 2003, L. Cosculluela MONTANER, «Reflexiones sobre los presupuestos constitucionales y de derecho comunitario europeo y los principios generales del Derecho público económico», pp. 111-137; S. MUÑOZ MACHADO, «Los límites constitucionales a la libertad de empresa», pp. 138-163; o G. FERNÁNDEZ FARRERES, «Reflexiones sobre el principio de subsidiariedad y la Administración económica», pp. 165-184.
} 
- La ley establece un amplio abanico de mecanismos de financiación, haciendo compatibles el clásico principio de transferencia del riesgo al concesionario con los sistemas de financiación y las eventuales aportaciones que realicen las Administraciones concedentes, que se reservan el control sobre la financiación misma de las obras y sobre el estado financiero del concesionario (artículos 220.4 y 253 a 260 LCAP).

- El equilibrio económico del contrato que viene a regular el artículo 248.2 LCAP, nuevamente en la redacción dada por la Ley 13/2003, tipifica los supuestos en los que procede el reequilibrio, recogiendo además los clásicos supuestos del ius variandi, el factum principis, la fuerza mayor y la revisión de precios.

- La Administración se erige a lo largo del texto en supervisora de otros valores y derechos, como los medioambientales, de ordenación del territorio y la protección de los derechos de terceros relacionados con la concesión, como es el caso de los prestamistas, tenedores de títulos o acreedores hipotecarios del concesionario (Disposiciones adicionales $1^{\mathrm{a}}, 2^{\mathrm{a}}$ y $13^{\mathrm{a}}$, y artículos 253 a 260 LCAP).

El conflicto entre los intereses que concurren en la construcción de obras públicas, en el contexto del Derecho Administrativo de la contratación pública, es el conflicto que subyace entre la necesidad de controlar la actuación administrativa (artículos 9.1, 9.3 y 106.2 de la Constitución, entre otros muchos) y la exigencia también constitucional de actuación eficaz de las Administraciones públicas, en el marco del Estado Social y Democrático de Derecho (artículos 1.1 y 103.1 del texto constitucional). De una parte se exigen, pues, mayores controles, dejando traslucir el papel cada vez más importante del poder judicial en la fiscalización de la actuación administrativa, y de otra se demanda mayor eficacia en la construcción de autovías, en las líneas ferroviarias o en la mejora general de las infraestructuras. A estos retos deberían responder las normas que regulan la contratación pública; normas imbuidas de la nueva cultura del pacto.

No obstante a ello, es claro que el Estado debe seguir jugando un papel significativo en la satisfacción de las necesidades públicas, siquiera sea como regulador de un mercado abierto a la competencia y caracterizado por un crecimiento constante de la demanda, y habrá por ello de estar investido de los correspondientes poderes jurídicos con los que desarrollar ese papel con eficacia y con sujeción a los pertinentes controles, pues no se trata en modo alguno de privatizar la contratación administrativa, sino de: 
a) Vincular a la Administración al Derecho Administrativo, esto es, al interés público en la ejecución y explotación de las obras públicas, con una atención especial a los derechos de los usuarios, y

b) Crear garantías para los contratistas, particularmente en el respeto de las reglas de la libre competencia en el mercado, salvaguardando la seguridad jurídica y los intereses empresariales de quienes comprometen su capital en proyectos públicos.

Sin embargo, una de las dificultades más relevantes en la configuración de este nuevo régimen de contratación administrativa es la proliferación normativa que desborda el mutable universo del Derecho Público de nuestros días ${ }^{6}$, y que en parte es resultado de la multiplicación de sujetos públicos creadores de normas. El proceso de reformas de la contratación pública arrancó con la Ley 13/1995, de 18 de mayo, de Contratos de las Administraciones Públicas; continuó con sus posteriores modificaciones, pasando por su refundición en el año 2000, y ha terminado, por el momento, con la Ley 13/2003 y con la modificación introducida por la Ley $62 / 2003$, de 30 de diciembre, de medidas fiscales, administrativas y del orden social, con motivo de las Sentencias de 15 de mayo y de 16 de octubre de 2003 del Tribunal de Justicia de las Comunidades Europeas, que planean sobre una de las deficiencias de la Ley de Contratos: la delimitación de su ámbito subjetivo de aplicación. Este ámbito pone de manifiesto la complejidad de las organizaciones públicas en su proceso imparable de descentralización funcional o por servicios, pero ahonda también peligrosamente en el fenómeno de la huida del Derecho administrativo.

Nuevas reformas otean en el horizonte de la mano del Derecho Comunitario. En particular, las Directivas 2004/18/CE del Parlamento Europeo y del Consejo, de 31 de marzo de 2004, sobre coordinación de los procedimientos de adjudicación de los contratos públicos de obras, de suministro y de servicios y 2004/17/CE del Parlamento Europeo y del Consejo, de 31 de marzo, sobre coordinación de los procedimientos de adjudicación de los contratos en los sectores del agua, de la energía, de los transportes y de los servicios postales, que deberán ser transpuestas antes del 31 de enero de 2006, y que persiguen el objetivo de simplificar, modernizar y flexibilizar el marco jurídico de los contratos públicos.

Tampoco se puede olvidar la aprobación de las siguientes leyes: la Ley 33/2003, de 3 de noviembre, del Patrimonio de las Administraciones Públicas; la Ley 38/2003, de 17 de noviembre, General de Subvenciones; 6 E. García de EnTERría, Justicia y seguridad jurídica en un mundo de leyes desbocadas, Civitas,
Madrid, 1999, p. 48. 
la Ley 39/2003, de 17 de noviembre, del Sector Ferroviario y la Ley 48/2003, de 26 de noviembre, de Régimen Económico y de Prestación de Servicios de los Puertos de Interés General, con indudables repercusiones todas ellas sobre la legislación de contratos.

Sobre la base de este complejo y novedoso marco normativo se efectuará una valoración crítica de la Ley 13/2003, de 23 de mayo, reguladora del contrato de concesión de obras públicas, prestando especial atención a las características que se infieren del texto y a los mecanismos de financiación privada de tales obras; unos mecanismos que conviven hoy con la financiación directa, con la financiación diferida del concesionario y con la novedosa modalidad contractual, en el ordenamiento jurídico estatal, consistente en la financiación mediante concesión de dominio público. Se abordarán además otras cuestiones tales como las deficiencias técnicas y de oportunidad de la ley; la independencia formal de ésta en el ámbito de la Ley de Contratos de las Administraciones Públicas y el controvertido ámbito subjetivo de aplicación de la ley.

\section{CARACTERÍSTICAS DE LA REGULACIÓN DEL CONTRATO DE CONCESIÓN DE OBRAS PÚBLICAS}

El legislador opta por insertar la regulación específica del contrato de concesión de obras públicas en la LCAP, siguiendo el criterio sostenido por el Consejo de Estado ${ }^{7}$. De este modo, se introduce en el seno de la regulación de los contratos administrativos típicos del libro II un nuevo título $\mathrm{V}$, que lleva por rúbrica «Del contrato de concesión de obras públicas», y que disciplina la vida del contrato atendiendo a sus peculiaridades. La Ley 13/2003 se compone de un artículo único que tiene por objeto modificar la LCAP para dar cabida a la nueva regulación del contrato de concesión de obras públicas, así como de 12 disposiciones adicionales, una disposición derogatoria y 5 disposiciones finales.

La concesión de obras públicas se podría definir como la convención por la que un ente público confía a otro sujeto la realización de una obra pública cuya posterior explotación consiste en la remuneración de este último en función de los resultados financieros de dicha explotación ${ }^{8}$. La

\footnotetext{
7 Vid., el dictamen del Consejo de Estado n. ${ }^{\circ}$ 3375/2001, de 5 de diciembre de 2001, sobre el Anteproyecto de Ley Reguladora del Contrato de Concesión de Obras Públicas.

${ }^{8}$ Cfr., Ruiz de OJeda y García Bernardo de Quirós, Comentarios a la Ley de Contratos de las Administraciones Públicas, Ed. Civitas.
} 
Comisión Europea ha considerado compatible la concesión con los principios y reglas del Derecho comunitario, definiéndola como el supuesto en el que las autoridades públicas confían a una parte la gestión de proyectos de infraestructura u otros servicios públicos en su nombre, en tanto que la otra parte asume la operación a su riesgo y ventura.

Tal como prevé la Exposición de Motivos de la ley, son cuatro las notas fundamentales que caracterizan la figura de la concesión, siendo la aproximación a su naturaleza jurídica la que puede conferir una mejor comprensión de la norma.

\section{a) Existencia de una obra pública}

Para poder hablar de contrato de concesión «se requiere, como presupuesto, que exista una obra pública entendida en sentido amplio como sinónimo de bien inmueble vinculado al interés público, creado por la actuación del contratista que realiza el proyecto promovido y aprobado por la Administración, y que explota económicamente, o sólo esto último, en el caso de que la concesión sea sólo de explotación»».

La obra pública, como realidad tangible, es el objeto mismo del contrato, a lo que se une el interés que su construcción merezca a la Administración concedente. Por eso, señala la Exposición de Motivos, la obra adquiere «su cabal significado para posibilitar el contrato cuando es susceptible de constituirse en soporte instrumental para la ejecución de actividades y servicios varios de interés público, incluido el que pueda desprenderse de su propia naturaleza cuando se destine al general uso o aprovechamiento».

El artículo 220.1 LCAP recoge este concepto y define el contrato en los siguientes términos:

«Aquel en cuya virtud la Administración pública o Entidad de Derecho Público concedente, otorga a un concesionario durante un plazo la construcción y la explotación o sólo la explotación de obras relacionadas en el artículo 120 (construcción y reparación de inmuebles, carreteras, aeropuertos, puertos, ferrocarriles, realización de trabajos que modifiquen la forma o sustancia del suelo, etc.), o en general de aquellas que siendo susceptibles de explotación sean necesarias para la prestación de servicios públicos de naturaleza económica o para el desarrollo de actividades o servicios económicos de interés general, reconociendo al concesionario el derecho a percibir una retribución consistente en la explotación de la propia obra, en dicho derecho acompañado del de percibir un precio o en cualquier modalidad establecida en este título».

9 F. SANZ GANDÁSEGUI, «El concepto de contrato de concesión de obras públicas (arts. 5, 7, 220 a 225)», en A. MENÉNDEZ MENÉNDEZ, (director): Comentarios a la nueva Ley 13/2003, op. cit., p. 93. 


\section{b) El riesgo concesional}

En lógica correspondencia con la existencia de una obra pública cuya financiación y explotación corresponden al concesionario, a cambio de una retribución pagada por el usuario o por la Administración, hay que mencionar el riesgo concesional, es decir, el modo en que el concesionario de la obra asume el compromiso de llevar a término la ejecución y explotación de la misma sabiendo que el desarrollo del contrato está expuesto a un riesgo, a un evento posible y dañoso ${ }^{10}$.

El principio de riesgo y ventura es consustancial a la contratación, tanto privada como pública. El artículo 98 LCAP proclama, en relación a esta última, que «la ejecución del contrato se realizará a riesgo y ventura del contratista sin perjuicio de lo establecido para los casos de fuerza mayor en el artículo 144». La asunción por el concesionario del riesgo y ventura concesional está recogida en los artículos $220,225,239,242 . b)$ y 248 LCAP. El riesgo concesional es el elemento que permite diferenciar el contrato de obra pública del contrato de concesión de obra pública, pues lo fundamental es que en este caso la obra no se financia por las Administraciones Públicas, sino por el concesionario, con ayuda o no de financiación externa. Si el riesgo fuese asumido por las Administraciones debería recalificarse el contrato ${ }^{11}$.

Por supuesto la licitación de una obra debe ir precedida de un cuidadoso estudio de viabilidad que asegure la rentabilidad del contrato, y además la Administración debe limitar el riesgo a lo razonable, garantizando la seguridad jurídica y el respeto a lo pactado en un contrato en el que la relación de colaboración entre el concedente y el concesionario tiene vocación de larga duración, ya que, como señala la Exposición de Motivos de la Ley 13/2003, «en un contrato de larga duración por naturaleza, la asunción del riesgo, ante la imposibilidad de predecir con un margen razonable de error en el futuro, no puede transformar el contrato en un negocio aleatorio por el que en coherencia se impone moderar adecuadamente los límites del riesgo, si se quieren atraer la participación del capi-

\footnotetext{
10 Vid., J. JimÉnEZ Cervantes, en la obra colectiva Comentarios a la Ley de Contratos de las Administraciones Públicas, coeditada por los Ministerios de Justicia, Fomento y el BOE, pp. 357 y 358.

11 A. RuIz OJEDA, «Análisis jurídico del futuro marco regulador de la concesión de obra pública. Algunas propuestas en el sector de carreteras», en Jornadas sobre contratación, construcción y explotación de carreteras en España. Asociación Española de la Carretera, 2002, pone de relieve la importancia de la traslación de riesgos al concesionario, considerándolo como un elemento esencial del contrato concesional, en línea con la Comunicación Interpretativa 2000/C 121/02 (DOCE de 29 de abril de 2000), de la Comisión Europea.
} 
tal y la iniciativa privadas en inversiones cuyo volumen exige el esfuerzo compartido de los sectores público y privado».

En este sentido, como se señalará más adelante, hay límites que pueden producir un reequilibrio concesional a través de las tarifas, y, por supuesto, las tradicionales figuras jurídicas de la fuerza mayor ${ }^{12}$, el factum principis, el riesgo imprevisible y el ius variandi. En todos estos casos, el carácter ajeno al concesionario de las causas de estas incidencias, la equidad y la propia conveniencia para el interés público (artículo 103.1 de la Constitución), determinan que se limite de alguna manera el riesgo al concesionario para evitar el fracaso de la concesión.

\section{c) El equilibrio económico concesional}

Ciertamente esta modulación del principio de riesgo y ventura del concesionario en beneficio de la viabilidad misma de la concesión está estrechamente relacionada con el principio del mantenimiento del equilibrio económico-financiero. El equilibrio viene constituido por aquellos elementos que, de acuerdo con el plan económico financiero propuesto por el contratista y aceptado por la Administración, estructuran financieramente el contrato, previendo la cuantía de la inversión, amortización, financiación, régimen y evolución tarifarios, etc. La ley prevé los oportunos ajustes en la concesión para evitar que el usuario soporte un peaje o un canon desproporcionados, con quebrando manifiesto de la equidad. No sólo los concesionarios podrán beneficiarse de este reequilibrio, sino el interés público y los propios usuarios. Acudiendo nuevamente a la Exposición de Motivos, «el equilibrio deberá restablecerse tanto si se ha roto en perjuicio como a favor del concesionario, produciendo unos efectos más allá de lo que se considera deseable o tolerable para la credibilidad de la institución y para el interés público, sin que por ello se elimine el interés del concesionario».

De este modo adquieren una importante significación las fórmulas de actualización de tarifas que puedan contener los pliegos de condiciones para asegurar «la justa retribución del esfuerzo y riesgo empresariales y el sacrificio razonable del usuario de la obra pública». El artículo 233.1.d),

\footnotetext{
12 Como señala F. SANZ GANDÁSEGUI, «El concepto de contrato de concesión de obras públicas (arts. 5, 7, 220 a 225)», en A. MENÉndez MEnÉndez, (director): Comentarios a la nueva Ley 13/2003, op. cit., p. 102, «sólo si la fuerza mayor determina de forma directa la ruptura sustancial de la economía de la concesión, el concedente asume la obligación de reequilibrar el contrato al mínimo de rentabilidad previsto por el concesionario en su plan económico financiero. En caso contrario, el concesionario asume las consecuencias de la fuerza mayor».
} 
en relación con el artículo 248.2.c) LCAP, establece que el concesionario quede comprometido con un nivel mínimo y un nivel máximo de rendimientos totales para cada concesión, de suerte que, en caso de que se sobrepasen dichos niveles durante el período que se determine, proceda la revisión del contrato, modificando las tarifas o el plazo concesional, entre otros medios, garantizando así la seguridad jurídica y la pervivencia del contrato en coyunturas distintas y evitando modificaciones contractuales sobrevenidas de difícil fundamentación.

\section{d) Diversificación de las fuentes de financiación}

La Ley 13/2003 no sólo opera una importante modificación de la legislación de contratos, sino que además introduce por vez primera en el ordenamiento jurídico distintas técnicas de financiación en la construcción y explotación privadas de infraestructuras públicas.

Se señalaba con anterioridad que la ley establece un amplio abanico de mecanismos de financiación, haciendo compatibles el clásico principio de transferencia de riesgo al concesionario con los sistemas de financiación y las eventuales aportaciones que realicen las Administraciones concedentes, y es que el principio del riesgo concesional es compatible con las ayudas públicas a la ejecución y a la explotación, pues de otro modo algunas concesiones no serían viables.

Conforme al artículo 224.3 LCAP la financiación pública sólo se habilita cuando concurran razones de rentabilidad económica o social, o exigencias derivadas del fin público o interés general de la obra pública, pudiendo proceder tanto de aportaciones del concedente como de las eventuales aportaciones de Administraciones Públicas distintas a la concedente a través de la suscripción de los oportunos convenios, o de la financiación que pueda provenir de otros organismos nacionales o internacionales, o de ambas instancias. Es así como se asegura una más fácil financiación del proyecto sin infringir el principio del riesgo concesional, que se mantiene como principio de base. El artículo 220.2 LCAP mantiene, en esta línea, la compatibilidad de dicho principio con los distintos sistemas de financiación de las obras que se regulan en la ley «y con las aportaciones a que pudiera obligarse la Administración concedente».

La ley distingue entre las aportaciones públicas durante la fase de ejecución de las obras [artículo 245.1.a)], cuyo régimen se regula en el capítulo concerniente a la construcción de la obra pública, y aquéllas 
que pueden producirse una vez concluidas las obras. Las primeras habrán de tener como finalidad garantizar la viabilidad económica de la explotación (artículo 247), pudiendo consistir en subvenciones al precio, anticipos reintegrables, préstamos participativos, subordinados o de otra naturaleza, $\mathrm{y}$, en casos excepcionales, y siempre por razones de interés público, serían posibles ayudas para la promoción de la utilización de la obra pública antes de que su explotación alcance el umbral mínimo de rentabilidad establecido formalmente.

Entre las posibilidades de financiación privada, que se desarrollarán más adelante, cabe ahora destacar que el texto introduce la posibilidad de que el concesionario explote las zonas comerciales anexas a la infraestructura (áreas de servicio, estaciones de ferrocarril) y la posibilidad de titulizar o hipotecar la infraestructura, considerando la circunstancia de que la concesión es un bien jurídico que se integra plenamente en el tráfico mercantil desde el momento de la perfección del contrato. Como contrapartida, las sociedades concesionarias se obligan a cumplir con la denominada «cláusula de progreso», por la que asumen el posterior mantenimiento de la obra pública y su adaptación a los distintos requerimientos técnicos, medioambientales o de seguridad que surjan en el tiempo.

Con respecto a la combinación de los recursos públicos y privados, la ley contempla la generalización del uso del denominado «peaje en sombra», por el que el concesionario construye y gestiona la vía y la Administración paga en función de los usuarios que la utilicen, así como el llamado modelo alemán, por el que el Estado abona el precio de la obra cuando recibe la misma una vez construida.

\section{LOS NUEVOS MECANISMOS DE FINANCIACIÓN DE OBRAS PÚBLICAS: EL RÉGIMEN ECONÓMICO-FINANCIERO DEL CONTRATO Y LA FINANCIACIÓN PRIVADA}

En consonancia con el objetivo de diversificar las fuentes de financiación que persigue la Ley 13/2003, quizás su nota característica más destacada, se analizan en este apartado la retribución del concesionario y los diversos mecanismos de financiación privada (artículos 253 a 260 LCAP).

La tradicional colaboración entre el sector público y el sector privado ejemplificada en la figura del contrato administrativo de obra pública sigue teniendo plena vigencia, pues a la postre sirve al objetivo de satis- 
facer el interés general. Sin embargo, habiéndose demostrado la necesidad de reducir a su mínima expresión el déficit público, debe enriquecerse el esquema colaborativo en el que la Administración financia, el contratista aporta el trabajo y los materiales y el usuario contribuye a la financiación con el pago de sus impuestos. Para ello, en el contexto del Derecho Administrativo Económico, es bien conocida la apertura del tradicional modelo concesional de obra pública al sector privado, sin merma de las debidas garantías que preserven el control público hasta el final. La participación de las inversiones privadas se suma a la explotación de la obra resultante por el concesionario o por otros inversores, y, finalmente, a las contraprestaciones por parte de los beneficiarios de la obra.

Conviene señalar que al amparo del artículo 225 LCAP la retribución del contratista podrá ser directa, mediante el precio que abone el usuario o la Administración por la utilización de la obra. Asimismo la retribución podrá provenir de los rendimientos derivados de la explotación de la zona comercial (el artículo 223 prevé zonas complementarias de explotación comercial por el concesionario) y, en su caso, de las aportaciones de la propia Administración de acuerdo con lo previsto en la ley, siempre que se respete el principio de asunción de riesgo por el concesionario. A estas aportaciones se refiere el artículo 224, junto a ciertas reglas sobre la financiación privada. La retribución y financiación del concesionario se completa, sin una gran sistemática, por los artículos 236, 245 a 247 y 253 a 260, que serán objeto de un análisis más detallado.

A) La retribución del concesionario o compensación económica, puede consistir en una o varias de las modalidades siguientes:

a) Un precio que abone el usuario o la Administración por la utilización de la obra, la tarifa o peaje, a aprobar por la Administración [artículo 249 e) LCAP] y recibir por el concesionario [artículo 242 a) LCAP]. Establece el artículo 246 que «las tarifas que abonen los usuarios por la utilización de las obras públicas serán fijadas por el órgano de contratación en el acuerdo de adjudicación. Las tarifas tendrán el carácter de máximas y los concesionarios podrán aplicar las tarifas inferiores cuando así lo estimen conveniente»; y que «las tarifas serán objeto de revisión de acuerdo con el procedimiento que determine el pliego de cláusulas administrativas particulares».

b) Una retribución por la utilización de la obra abonada por la Administración (artículo 246.4 LCAP): el llamado peaje en sombra (sha- 
dow toll, en inglés). La Administración paga al contratista la compensación por el peaje que en el régimen común pagaría el usuario, tomando en consideración la utilización de la obra. Para ello sería necesario, por ejemplo, efectuar un recuento de vehículos. En España se ha llevado a la práctica, por vez primera, en la Comunidad de Madrid (en la llamada M-45).

c) Otras aportaciones de la Administración, que el artículo 224.3 LCAP limita al supuesto de que «existan razones de rentabilidad económica o social, o concurran singulares exigencias derivadas del fin público o interés general de la obra objeto de concesión». Pueden consistir en la financiación conjunta de la obra, mediante aportaciones dinerarias o no dinerarias, subvenciones o préstamos reintegrables, con o sin interés, o préstamos participativos, de acuerdo con el correspondiente pliego de cláusulas administrativas particulares y con respeto al principio de asunción del riesgo del concesionario.

El artículo 236.2 LCAP regula la ayuda de la Administración mediante la ejecución o financiación parcial de la obra, y establece que dicha financiación se abonará en los términos pactados, durante la ejecución de las obras, de acuerdo con el artículo 145 del mismo cuerpo legal, o bien una vez que las obras hayan concluido, conforme a lo dispuesto en el artículo 245. La ley contempla, en definitiva, las certificaciones como parte de la financiación de la obra, partiendo de la base de que la retribución del concesionario consiste en la explotación de la obra y que este sistema es sólo admisible parcialmente.

De acuerdo con el artículo 245 es posible también una aportación de la Administración una vez concluidas las obras o incluso al término de la concesión, siendo de aplicación la normativa sobre contratos de obra bajo la modalidad de abono total (el llamado sistema alemán). Estas aportaciones podrán ser de carácter no dinerario, como por ejemplo los bienes inmuebles que se entreguen al concesionario y que se integrarán en el patrimonio afecto a la concesión, destinándose al uso previsto en el proyecto de obra, y revirtiendo a la Administración en el momento de su extinción. Estas aportaciones podrán provenir de la Administración concedente y de cualesquiera Administraciones y organismos nacionales o internacionales (artículo 224.4 LCAP).

En cuanto a las aportaciones públicas a la explotación el artículo 247 LCAP establece las siguientes: 
— «Subvenciones al precio, anticipos reintegrables, préstamos participativos, subordinados o de otra naturaleza, aprobados por el órgano de contratación para ser aportados desde el inicio de la explotación de la obra, o en el transcurso de la misma cuando se prevea que vayan a resultar necesarios para garantizar la viabilidad económicofinanciera de la concesión. La devolución de los préstamos y el pago de los intereses devengados en su caso por los mismos se ajustarán a los términos previstos en la concesión.

- Ayudas en los casos excepcionales en que, por razones de interés público, resulte aconsejable la promoción de la utilización de la obra pública antes de que su explotación alcance el umbral mínimo de rentabilidad».

d) Finalmente, el artículo 246.5 LCAP regula los rendimientos procedentes de la explotación de la zona comercial. El artículo 223 LCAP desarrolla el precepto señalando que «atendiendo a su finalidad, las obras públicas podrán incluir, además de las superficies que sean precisas según su naturaleza, otras zonas o terrenos para la ejecución de actividades complementarias, comerciales o industriales que sean necesarias o convenientes para la utilidad que prestan a los usuarios de las obras y que sean susceptibles de un aprovechamiento económico diferenciado, tales como establecimientos de hostelería, estaciones de servicio, zonas de ocio, estacionamientos, locales comerciales y otros susceptibles de explotación».

B) Por otra parte, la LCAP, tras la reforma operada por la Ley 13/2003, cuida especialmente el régimen de financiación privada del concesionario, «sobre la base indudable de que una mejor, más fácil y más segura financiación de aquél redunda en beneficio de la actividad concesional y, por ende, de la Administración $\rangle^{13}$.

El Consejo de Estado emitió un juicio general muy favorable en esta materia (Dictamen n. ${ }^{\circ} 3.375 / 2001$, de 5 de diciembre):

«No puede por menos (el Consejo de Estado) que encomiar la voluntad de la autoridad consultante de incorporar al ordenamiento jurídico administrativo los mecanismos y técnicas de financiación a la construcción y explotación de las obras públicas, pues si bien tales mecanismos siempre han encontrado arraigo en el ámbito mercantil y financiero, su aplicación a la Administración Pública y a la actividad administrativa ha tropezado con no pocas dificultades derivadas de su falta de regulación y previsión expresa».

\footnotetext{
${ }^{13}$ F. GarCía GómeZ De MerCado, «Contratos y concesiones de obras: la Ley 13/2003, reguladora del contrato de concesión de obras públicas», Revista Jurídica de la Comunidad de Madrid, n. ${ }^{\circ}$ 16, mayo-agosto 2003, op. cit. p. 46.
} 
El artículo 224.2 LCAP señala que «el concesionario podrá recurrir a la financiación privada para hacer frente a sus obligaciones contractuales en los términos y condiciones que se establecen en esta Ley. Además de los medios previstos en el capítulo IV de este título podrá obtener financiación mediante la contratación de préstamos o créditos con entidades de crédito de acuerdo con el ordenamiento jurídico vigente. Dichos contratos deberán ser comunicados al órgano de contratación en el plazo de un mes desde su suscripción. Asimismo, el concesionario podrá recurrir a otros medios de financiación privada previa autorización del órgano de contratación».

Los medios de financiación previstos en el citado capítulo son los que siguen: la emisión de obligaciones y otros títulos, la incorporación a títulos negociables de los derechos de crédito del concesionario, la hipoteca de la concesión y los créditos participativos.

Puesto que de financiación privada se trata, el artículo 260 LCAP aclara que «el conocimiento de las cuestiones litigiosas que se susciten por aplicación de los preceptos contenidos en este capítulo será competencia del orden jurisdiccional civil, salvo para las actuaciones que, con arreglo a lo dispuesto en dichos preceptos, se atribuyen a la Administración concedente, y en las que será competente el orden jurisdiccional contencioso-administrativo».

\section{a) Emisión de obligaciones}

El concesionario podrá apelar al crédito en el mercado de capitales, tanto exterior como interior, mediante la emisión de toda clase de obligaciones, bonos u otros títulos semejantes, pudiendo contar con el aval del Estado, Comunidades Autónomas o Entes Locales (artículo 253). El límite legal viene dado por la emisión de títulos cuyo plazo de reembolso total o parcial finalice en fecha posterior al término de la concesión. Asimismo la emisión deberá ser comunicada al órgano de contratación en el plazo máximo de un mes desde la fecha en que la emisión se realice, considerándose así que esta comunicación es la mejor manera de efectuar el oportuno seguimiento de la situación financiera del concesionario.

\section{b) Incorporación a títulos negociables de los derechos de crédito del concesionario}

Podrán emitirse valores que representen una participación en uno o varios de los derechos de crédito (de uno o de varios ejercicios económi- 
cos) a favor del concesionario consistentes en el derecho al cobro de tarifas, los ingresos que pueda obtener por la explotación de los elementos comerciales relacionados con la concesión, así como los que correspondan a las aportaciones que, en su caso, deba realizar la Administración. La cesión de estos derechos se formalizará en escritura pública, representándose los valores negociables en títulos o anotaciones en cuenta. Los créditos incorporados a los valores reseñados tienen el carácter de separables en caso de quiebra del concesionario y los tenedores de los valores ocuparán el mismo lugar en la prelación que el acreedor hipotecario.

La cuestión de la inscripción registral de estos valores tiene especial importancia porque las concesiones administrativas deben inscribirse en el Registro de la Propiedad y porque el artículo 254.1 in fine LCAP exige que la emisión de estos valores cuente con la correspondiente autorización administrativa previa del órgano de contratación, «cuyo otorgamiento sólo podrá denegarse cuando el buen fin de la concesión u otra razón de interés público relevante lo justifiquen». La vigilancia administrativa no sólo se extiende a la emisión, sino a su suscripción y tenencia, dado el interés público que en todo momento se predica de la concesión de obra pública.

En caso de que se produzca causa de resolución de la concesión imputable al concesionario sin que los acreedores hayan obtenido el reembolso correspondiente a sus títulos, la Administración concedente podrá acordar el secuestro de la concesión a fin de satisfacer los derechos de los acreedores sin que el concesionario pueda percibir ingreso alguno; o resolver la concesión, acordando con el representante de los acreedores la cuantía de la deuda y las condiciones en que la misma deberá ser amortizada.

\section{c) Hipoteca de la concesión}

A ella se refiere el artículo $107.6^{\circ}$ de la Ley Hipotecaria, cuyo texto refundido fue aprobado según Decreto de 8 de febrero de 1946, en los siguientes términos:

«Las concesiones administrativas de minas, ferrocarriles, canales, puertos y otras obras destinadas al servicio público, y los edificios o terrenos que, no estando directa y exclusivamente destinados al referido servicio, pertenezcan al dominio particular, si bien se hallen agregados a aquellas obras, quedando pendiente la hipoteca, en el primer caso, de la resolución del derecho del concesionario».

La modificación que la Ley 13/2003 opera en la legislación de contratos viene a completar esta regulación de la hipoteca de la concesión en sus 
artículos 255 a 258 , disponiendo que «las concesiones de obras públicas con los bienes y derechos que lleven incorporados serán hipotecables conforme a lo dispuesto en la legislación hipotecaria, previa autorización del órgano de contratación» si bien «no se admitirá la hipoteca de concesiones de obras públicas en garantía de deudas que no guarden relación con la concesión correspondiente», de modo que la hipoteca se limita a las obligaciones que surjan de la financiación de la propia concesión. Las solicitudes referentes a las autorizaciones administrativas se resolverán por el órgano competente en el plazo de un mes, debiendo entenderse desestimadas si no resuelven y notifican en plazo, en consonancia con el artículo 43.2 de la Ley 30/1992, de 26 de noviembre, de Régimen Jurídico de las Administraciones Públicas y del Procedimiento Administrativo Común.

El artículo 256.1 LCAP viene a establecer una acción administrativa de deterioro o devastación. «Cuando el valor de la concesión hipotecada sufriera grave deterioro por causa imputable al concesionario, el acreedor hipotecario podrá solicitar al órgano de contratación pronunciamiento sobre la existencia efectiva de dicho deterioro. Si éste se confirmara podrá, asimismo, solicitar de la Administración que, previa audiencia del concesionario, ordene a éste hacer o no hacer lo que proceda para evitar o remediar el daño, sin perjuicio del posible ejercicio de la acción de devastación prevista en el artículo 117 de la Ley Hipotecaria. No obstante, en el caso de ejercitarse la acción administrativa prevista en este apartado, se entenderá que el acreedor hipotecario renuncia a la acción prevista en el citado artículo 117 de la Ley Hipotecaria».

Asimismo, en aras a proteger los derechos del acreedor hipotecario el artículo 256, en su apartado 2, añade que:

"Cuando procediera la resolución de la concesión por incumplimiento de alguna de las obligaciones del concesionario, la Administración, antes de resolver, dará audiencia al acreedor hipotecario por si éste ofreciera subrogarse en su cumplimiento y la Administración considerara compatible tal ofrecimiento con el buen fin de la concesión».

La hipoteca, como toda garantía real, implica la eventual enajenación del bien dado en garantía, con lo que puede suponer de novación subjetiva del contrato. Además, deberá haberse inscrito la propia concesión administrativa, como derecho real que es, en el Registro de la Propiedad (artículos 31 y 60 y ss. del Reglamento Hipotecario). Dada la exigencia de autorización administrativa para la cesión del contrato se ha considerado que la hipoteca exige también esta autorización (artículo 114 LCAP), como enajenación potencial, y así se prevé en el artículo 255 LCAP. Además el artículo 257 exige la autorización del nuevo concesionario, y dis- 
pone que «el adjudicatario en el procedimiento de ejecución hipotecaria quedará subrogado en la posición del concesionario, previa autorización administrativa».

Conforme al artículo 258.1 LCAP, «cuando procediera la resolución de la concesión y existieran titulares de derechos o cargas inscritos o anotados en el Registro de la Propiedad sobre la concesión, se observarán las siguientes reglas:

a) La Administración, comenzado el procedimiento, deberá solicitar para su incorporación al expediente certificación del Registro de la Propiedad, al objeto de que puedan ser oídos todos los titulares de tales cargas y derechos.

b) El registrador, al tiempo de expedir la certificación a que se refiere el párrafo anterior, deberá extender nota al margen de la inscripción de la concesión sobre la iniciación del procedimiento de resolución.

c) Para cancelar los asientos practicados a favor de los titulares de las citadas cargas y derechos, deberá mediar resolución administrativa firme que declare la resolución de la concesión y el previo depósito a disposición de los referidos titulares de las cantidades y eventuales indemnizaciones que la Administración debiera abonar al concesionario conforme a lo previsto en el artículo 266».

Por último, y sin perjuicio de que la subasta quedara desierta, con la consiguiente adjudicación al acreedor en pago, cuando la resolución de la concesión proceda por causa imputable al concesionario, los citados titulares de derechos y cargas podrán ejercitar, por su orden, el derecho de subrogarse en la posición jurídica del concesionario, siempre que, por reunir los requisitos necesarios para ello, fueran autorizados previamente por el órgano de contratación (artículo 258.2 LCAP).

\section{d) Los créditos participativos}

Regula el artículo 259 LCAP esta forma de financiación privada consistente en la devolución del capital sobre la base de entregas fijas y variables, en función de los beneficios de la concesión. «Se admiten los créditos participativos para la financiación de la construcción y explotación, o sólo la explotación, de las obras públicas objeto de concesión. En dichos supuestos la participación del prestamista se producirá sobre los ingresos del concesionario»». 
Será posible además que el concesionario amortice anticipadamente el capital prestado en las condiciones que se pacten en beneficio de la libertad o autonomía del contratista. Sin embargo, excepcionalmente, las Administraciones Públicas podrán contribuir a la financiación de la obra mediante el otorgamiento de créditos participativos, y en tales casos, y salvo estipulación expresa en contrario, el concesionario no podrá amortizar anticipadamente el capital prestado, a no ser que la amortización anticipada implique el abono por el concesionario del valor actual neto de los beneficios futuros esperados según el plan económico-financiero revisado y aprobado por el órgano competente de la Administración en el momento de la devolución del capital.

Bastará la comunicación al órgano de contratación de la obtención de estos créditos en el plazo máximo de un mes desde la fecha en que cada uno hubiera sido concedido, lo que a todos efectos no traba demasiado la capacidad empresarial del concesionario para diseñar y ejecutar sus estrategias de mercado, y hace posible que la Administración tenga un adecuado conocimiento de las operaciones del concesionario que incidan en la vida de la concesión.

\section{VALORACIÓN GENERAL DE LA LEY 13/2003 ANTE EL HORIZONTE DE UNA NUEVA LEY DE CONTRATOS DEL SECTOR PÚBLICO}

Al margen de los objetivos generales que el texto cumple, conviene hacer referencia, para finalizar, a algunas cuestiones técnicas y de oportunidad que afloran en la descripción general del contenido de la ley y de sus principales características.

La integración formal de esta ley en el marco jurídico general de la contratación pública (la LCAP), promovida por el Consejo de Estado, no resuelve algunas cuestiones como la aplicación de las disposiciones que indican lo que es básico. Así, la disposición final primera de la LCAP, que no ha sido modificada en este punto por la Ley 13/2003, convive con la disposición final primera de esta última norma, que señala lo que es básico, ampliando sustancialmente, en el ámbito del contrato de concesión de obra pública, el ya de por sí amplio contenido que la normativa básica del Estado tiene en el seno de la LCAP. Sucede así que preceptos no básicos conforme a esta última ley lo van a ser de acuerdo con la Ley 13/2003 sin justificación aparente.

Asimismo, como la ley pretendía en un principio cohonestarse con la LCAP y constituir, al propio tiempo, una disposición legal autónoma, el 
resultado es que muchos de sus preceptos repiten innecesariamente los generales de la LCAP (v. gr. las causas de resolución del actual artículo 264 LCAP). No menores son las dudas interpretativas que surgen al no haberse reformado hasta la fecha el Reglamento General de la Ley de Contratos de las Administraciones Públicas, aprobado por el Real Decreto $1098 / 2001$, de 12 de octubre.

La introducción del contrato de concesión de obra entre los contratos típicos no se hace con plena sujeción a la legislación de contratos, sino exclusivamente al Título V del Libro II de la LCAP, a sus disposiciones de desarrollo y a la legislación sectorial específica en cuanto no se oponga a dicho Título (artículo 7.2 LCAP), de tal manera que este cuerpo normativo funciona de manera autónoma dentro de la LCAP, pese a que sus insuficiencias necesitan ser cubiertas por el mecanismo interpretativo de la aplicación de principios contenidos en dicha ley.

Un aspecto positivo de la ley es su carácter troncal u horizontal, pues la norma nace con el propósito declarado de sustentar y servir de fuente reguladora del ámbito concesional, cohesionando y dotando de unidad a las leyes sectoriales, sin perjuicio de sus especialidades propias. Es lo lógico, tanto desde un plano conceptual como procedimental, que se afronte la heterogeneidad de las infraestructuras a las que pueda aplicarse la legislación concesional con unas normas comunes aplicables a todos los sectores. Más allá de las necesarias adaptaciones de la legislación de contratos, la ley contiene una regulación completa del contrato de concesión.

Por otra parte, esta modalidad contractual de obras debe diferenciarse y delimitarse jurídicamente de la figura de otro contrato típico: el contrato de gestión de servicios públicos, y, particularmente, la concesión de servicios [artículo 156 a) LCAP]. Puede ocurrir que existan contratos de concesión de obras públicas que sean soporte de un servicio público, y que la explotación de la obra se solape con la gestión del servicio, lo que entra dentro del ámbito de este otro contrato típico y deberá resolverse atendiendo a la prestación que tenga más importancia, de igual forma que en los contratos mixtos (artículo 6 LCAP) ${ }^{14}$. Igualmente, la jurisprudencia del Tribunal Supremo viene sosteniendo la tesis del carácter mixto del contrato de concesión de obra (STS de 6 de junio de 1997, RJA 5219),

\footnotetext{
14 En este sentido se pronuncia F. GARCía GómEZ DE MERCADO, «Contratos y concesiones de obras: la Ley 13/2003 ...», op. cit., p. 20. También se hacen eco de esta distinción R. FERNÁNDEZ MONTALVO, en JiMÉNEZ APARICIO (coordinador): Comentarios a la legislación de contratos de las Administraciones Públicas, Aranzadi, $2^{a}$ ed., 2002, pp. 1232 y ss.
} 
subrayando el fenómeno de la accesoriedad concesional, subordinando la concesión demanial a la de servicio público ${ }^{15}$.

Una de las cuestiones más espinosas de la ley es la delimitación de su ámbito subjetivo de aplicación. La ley establece en su artículo 220.5 que «el régimen del contrato de concesión de obras públicas previsto en este Título será aplicable a todas las entidades de derecho público cualquiera que sea su régimen jurídico de contratación y denominación». Esta previsión llega más allá de lo establecido en el artículo 1.3 LCAP y en su disposición adicional undécima, referida a los contratos en los sectores del agua, de la energía, de los transportes y de las telecomunicaciones, lo que en la práctica se traduce en que el régimen jurídico del contrato de concesión de obras públicas se aplica a todas las Administraciones Públicas y Entidades de Derecho Público, con independencia del tipo de entidad, en tanto que las restantes previsiones de la LCAP sólo se aplican a las Administraciones Públicas y Organismos Autónomos y, de forma parcial, a las restantes Entidades de Derecho Público.

A su vez, la Ley 13/2003 no parece aplicable a las empresas privadas que gocen de un derecho especial o exclusivo otorgado por una autoridad competente, en virtud de disposición legal, reglamentara o administrativa. Así se desprende de la lectura de su disposición adicional duodécima, que es consecuencia directa del proceso de liberalización y despublificación de un considerable volumen de infraestructuras y servicios en los ámbitos energéticos y de telecomunicaciones cuya titularidad venía siendo pública. Señala esta disposición adicional que «se regirán por su legislación específica las obras e instalaciones relacionadas con el sistema de transporte y distribución de energía eléctrica, las telecomunicaciones, el gas y los hidrocarburos».

Finalmente, las sociedades mercantiles, al amparo de la disposición adicional sexta de la LCAP, en la redacción dada por la Ley 62/2003, de 30 de diciembre, de medidas fiscales, administrativas y del orden social, ajustarán su actividad contractual a los principios de publicidad y concurrencia, salvo que la naturaleza de la operación a realizar sea incompatible con estos principios. Esta nueva redacción es consecuencia de que el Tribunal de Justicia de las Comunidades Europeas ha declarado el incumplimiento por parte de España de distintas directivas comunitarias, en sen-

\footnotetext{
15 F. SANZ GANDÁSEGUI, «El concepto de contrato de concesión de obras públicas (arts. 5, 7, 220 a 225)», en A. MENÉNDEZ MENÉNDEZ, (director): Comentarios a la nueva Ley 13/2003, op. cit., pp. 97-99 mantiene que el contrato de concesión de obras es un contrato con identidad propia, distinto al contrato de obras y al de gestión de servicios públicos.
} 
tencias de 15 de mayo y de 16 de octubre de 2003. Una próxima reforma de la LCAP debería de clarificar este ámbito subjetivo, inspirándose a tales efectos en la Ley 47/2003, de 26 de noviembre, General Presupuestaria, así como salvar otras deficiencias técnicas de la ley vigente, ya esbozadas. 